\title{
HEALTH INFORMATION SYSTEM
}

\author{
Masumi Minowa ${ }^{1}$, Masayuki Hayashi ${ }^{2}$, Akiko Kitai ${ }^{3}$, Atsushi Koyama ${ }^{3}$ and Yatsuho Otani ${ }^{4}$
}

\begin{abstract}
Outline of selected ones among a number of nationwide surveys related to health and welfare services ( 90 surveys as of 1995) conducted mainly by the Ministry of Health and Welfare periodically in Japan is described. That is, history, purpose, coverage, date, contents, data collection procedure, tabulation and publication were explained in regard to : (1) Population Census, (2) Vital Statistics, (3) Patient Survey, (4) Infectious Disease Surveillance System, (5) Comprehensive Survey of Living Conditions of People on Health and Welfare, (6) Census on Medical Care Institutions, (7) Hospital Report, (8) Survey on Physicians, Dentists and Pharmacists, (9) Statiatical Report on Public Health Administration Sevices, (10) Survey on Social Welfare Institutions, and (11) National Nutrition Survey.

On-line data service system of the Ministry of Health and Welfare is also briefly mentioned. J Epidemiol, 1996 ; 6 : S147-S157.
\end{abstract}

health, welfare, statistics, nationwide, on-line data service

\section{SELECTED SURVEYS FOR HEALTH AND WELFARE SERVICES}

\section{Population Census}

\section{History}

The population censuses in Japan have been conducted every five years since 1920. The last 1995 Population Census was the sixteenth one.

The population censuses include large-scale censuses and simplified censuses. The censuses taken every ten years starting 1920 are the large-scale censuses, while the censuses taken quinquennially between the large-scale decennial censuses are the simplified ones. During the prewar period the main difference between the two was the number of questions asked in the census. In the simplified one, questions were limited to basic characteristics of population, i.e., name, sex, age, marital status, etc., while the large-scale census covered questions on socio-economic characteristics such as occupation and industry in addition to the basic characteristics of population.
After World War II, the scale of census-taking has generally been amplified so as to satisfy the increased demands from the variety of users of the census results. The 1990 Population Census was taken as a large-scale one.

\section{Purpose}

To provide data on the present situation of pupulation in Japan.

\section{Coverage}

The whole population in Japan. A person is enumerated at the place where he or she usually lives and is counted in the population of that area.

Date

As of 0:00 A.M. of 1 October of the census year.

Contents of Questionnaire for the 1990 Population Census

(i) For household member

Name, sex, date of birth, relationship to the head of the

\footnotetext{
Received and accepted October 6, 1995.

${ }^{1}$ Department of Epidemiology, National Institute of Public Health, Tokyo, Japan.

${ }^{2}$ Department of Demography and Health Statistics, National Institute of Public Health, Tokyo, Japan.

${ }^{3}$ Statistics and Information Department, Ministry of Health and Welfare, Japan.

${ }^{4}$ Health Promotion and Nutrition Division, Health Service Bureau, Ministry of Health and Welfare, Tokyo, Japan.

Address for correspondence : Masumi Minowa, Department of Epidemiology, National Institute of Public Health, 4-6-1 Shirokanedai Minato-ku Tokyo, 108 Japan.
} 
household, marital status, nationality, previous address five years ago, educational record, type of employment (permanent/part-time employment), industry, occupation, employment status (rank in enterprise), place of work or location of school, transportation to the place of work or location of school, commutation time.

\section{(ii) For household}

Type of household (extended/nuclear family, etc.), number of household members, source of income, type of tenure (purchased/rental), number of dwelling rooms, total floor space, type of building (wooden/reinforced concrete) and number of stories.

\section{Data Collection Procedure}

The field enumeration of the 1990 Population Census was conducted, within their respective jurisdictions, by the mayors or the heads of city, ward and village, under the supervision of the governments of prefectures. The whole procedure was planned and administered by the Statistics Bureau, the Prime Minister's Office.

\section{Tabulation and Publication}

The Statistics Bureau, the Prime Minister's Office takes charge of the whole tabulation and releases the results through publications and other media.

\section{Vital Statistics (Figure 1)}

\section{History}

The Household Registration System was established and came to function as a permanent source of vital statistics in Japan in 1872. The jurisdiction of vital statistics system was transferred from the Statistics Bureau, Prime Minister's Office to the Ministry of Health and Welfare in 1947, with a view to making full use of the collected data mainly for public health activities.

\section{Method of Collecting Data}

The basic characteristic of the present vital statistics system is based on the Household Registration System, which registers each individual's legal status under the jurisdiction of the Ministry of Justice. According to the provisions of the Household Registration Law, vital events of birth, death, marriage and divorce have to be reported to the head of the local administrative office. The event of stillbirth (fetal death) also has to be reported under the provisions of the Stillbirth Report.

A Birth Report has to be accompanied with a birth certificate by the physician or the midwife who attended the delivery. The report should be submitted by either father, mother, a person who lives with them, or anyone who attended the delivery, within 14 days after the birth. A death has to be reported with a doctor's death certificate or autopsy report. The death report has to be submitted by the relative or anyone who lived with the deceased, the landowner, or the custodian, within 7 days after the death or the time when the dealth was known. The report of stillbirth has to be made with a doctor's or midwife's certificate of stillbirth, and is to be reported by father, mother, any person who lives with them, or anyone who attended the delivery, within 7 days after the stillbirth. The channel of collecting vital statistics data can be illustrated in the following chart:

\section{Publications of Vital Statistics}

The results of vital statistics are published by the Statistics and Information Department, Ministry of Health and Welfare

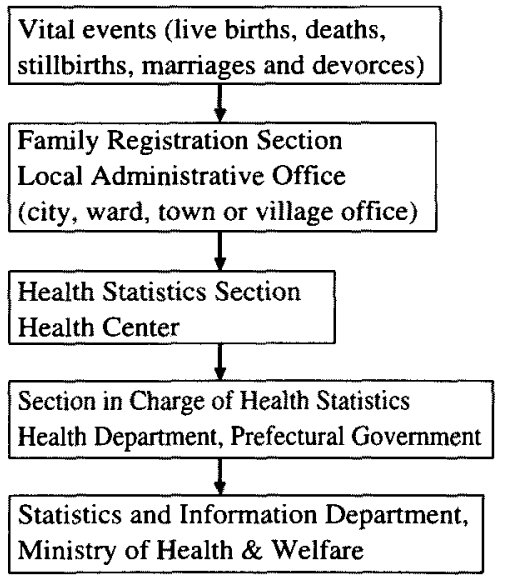

1. Reporting.

2. Report accepted after scrutiny.

3. Vital statistics schedules prepared.

4. The schedules forwarded to the Health Centers immediately.

5. Entire schedules examined.

6. The schedules submitted to the Prefectural Government before the 25 th of every month.

7. Schedules examined.

8. The schedules submitted to the Ministry of Health and Welfare before the 5th of the following month.

9. Vital statistics are tabulated, analysed and published monthly as well as annually. 10. Supervision and guidance given to local authorities in the handling of vital statistics.

Figure 1. Channel of collecting vital statistics data 


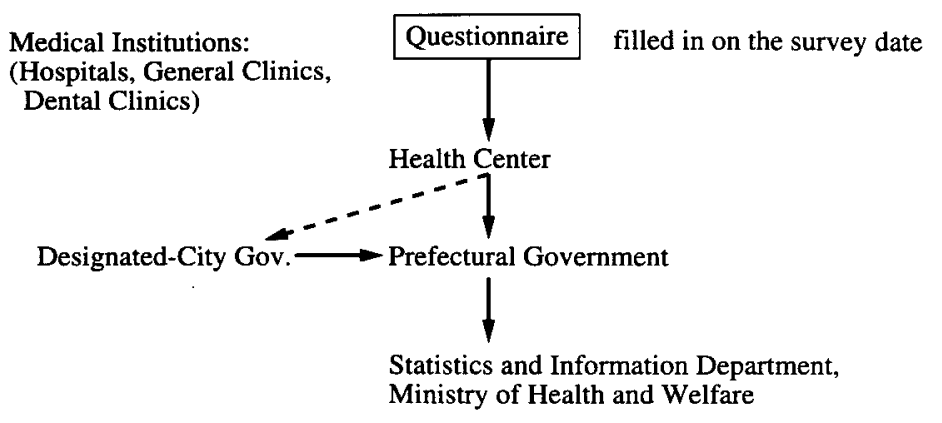

Figure 2. Patient Survey

on a periodical basis in the following three kinds of publication : a. Monthly Brief Report of Vital Statistics

This Monthly Brief Report covers total figures of live births, deaths, stillbirths, marriages and divorces by prefecture. It should be noted that the figures stated in this report represent only the number of forms submitted for each type of vital events forwarded from Prefectural Govenments and received by the Ministry of Health and Welfare. This is published 2 months later.

b. Monthly Report of Vital Statistics

This Monthly Report containing the figures derived from the processed data is published 5 months after the month of occurrence of the vital events. This report covers a wider variety of detailed tables of results.

\section{c. Annual Report of Vital Statistics}

The Annual Report is a fundamental one among the periodical publications on vital statistics. The Annual Report includes a wide variety of detailed tables and presents final tabulations of vital statistics in Japan. The Annual Report is published one year after the year of occurrence.

\section{Patient Survey (Figure2)}

\section{History}

Before formal establishment of the Patient Survey in 1953, morbidity data had been collected annually since 1948 .

A major modification in the structural management and procedure was made in 1984. The address of the patient was added to the questionnaire and the sampling rate was increased. Since then the survey has been conducted every three years.

\section{Purpose}

To obtain fundamental information about patients treated in medical institutions.

\section{Coverage}

In the 1993 survey, about 7,000 hospitals, 6,000 general clinics and 1,000 dental clinics were randomly selected after stratification by prefecture. The sampling rates were : $70 \%$ for hospitals, $7.5 \%$ for general clinics and $2.0 \%$ for dental clinics.

Date

As of one designated day of October (since 1984 once every 3 years).

\section{Contents of Reporting Forms}

Sex, date of birth, address, type of treatment, diagnosis, specialty of medical facility, type of health insurance, time of the last visit, and route of reference

\section{Data Collection Procedure}

The questionnaires completed by the responsible institution are submitted to the health center of the area. Those collected are sent to the Statistics and Information Department of the Ministry of Health and Welfare through the prefectural and, where applicable, the designated-city governments.

\section{Tabulation and Publication}

The Statistics and Information Department is responsible for the tabulation and releases the results through publications and other media.

\section{Infectious Disease Surveillance System (Figure 3)}

The Infectious Disease Surveillance System designed to investigate epidemics of various communicable diseases on a weekly or monthly basis was introduced in 1981 in all prefectures and large municipalities in collaboration with over 3,000 designated clinics/hospitals. This system was then developed into a computerized on-line system in 1987 to facilitate communication and analysis of surveillance information. The outline of the surveillance system is illustrated in the following figure. The number of designated clinics/hospitals was allocated in proportion to the population served by each health center, including clinics/hospitals of pediatrics, internal medicine, urology and dermatology. 


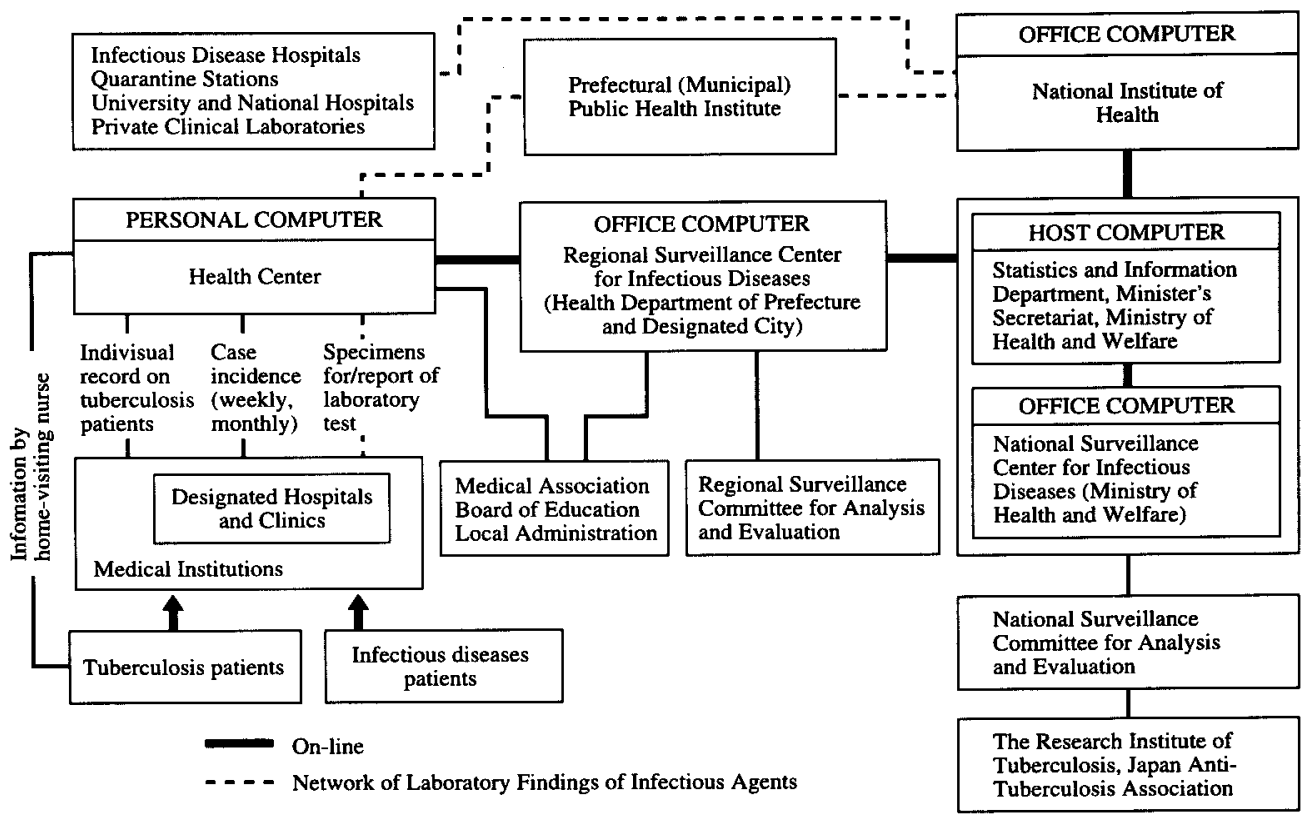

Figure 3. Infectious Disease Surveillance System

The following 26 diseases are included in this surveillance system : measles, rubella, chickenpox, mumps, pertussis, streptococcal infection, atypical pneumonia, infectious gastroenteritis, infantile vomiting and diarrhea, hand, foot and mouth disease, erythema infectiosum, exanthema subitum, herpangina, influenza, acute febrile mucocutaneous lymphnode syndrome, pharyngo-conjunctival fever, epidemic keratoconjunctivities, acute hemorrhagic conjunctivitis, meningitis, encephalomyelits, hepatitis (A,B, non-A, non-B), gonorrhea, genital chlamyudial infection, genital herpes, condyloma acuminatum, and trichomoniasis.

5. Comprehensive Survey of Living Conditions of People on Health and Welfare (Figure 4)

\section{History}

Ad-hoc surveys of households had been conducted by the Ministry of Health and Welfare since 1945. The Comprehensive Survey of Living Conditions of People on Health and Welfare has been conducted since 1986 .

\section{Purpose}

To provide data on living conditions such as the health status, pensions, welfare, and incomes of people in Japan.

\section{Coverage}

5,240 census enumeration districts are stratified and randomly sampled, and all households and household members in those districts are surveyed. The sample comprises approxi- mately 260,000 households and 800,000 household members.

\section{Date}

A designated day in June or July

Detailed survey: every 3 years

Brief survey: annually

\section{Contents of Questionnaire}

(i) Questionnaire on Household

Number of household members, sex, date of birth, condition of disabled person (s), occupational status, social insurance, and pension system.

(ii) Questionnaire on Health

Activities of daily living (ADL), symptoms, daily activities for health, and medical consultation.

(iii) Questionnaire on Income

Status of income, tax, and social welfare.

(iv) Questionnaire on Saving

Status of saving.

\section{Data Collection Procedure}

The interviewer-administered questionnaire on household and income and self-administered questionnaire on health and saving, and the Questionnaire on Household and Health are submitted to the Health Center. The Questionnaire on Income and Saving collected by the investigator are submitted to 


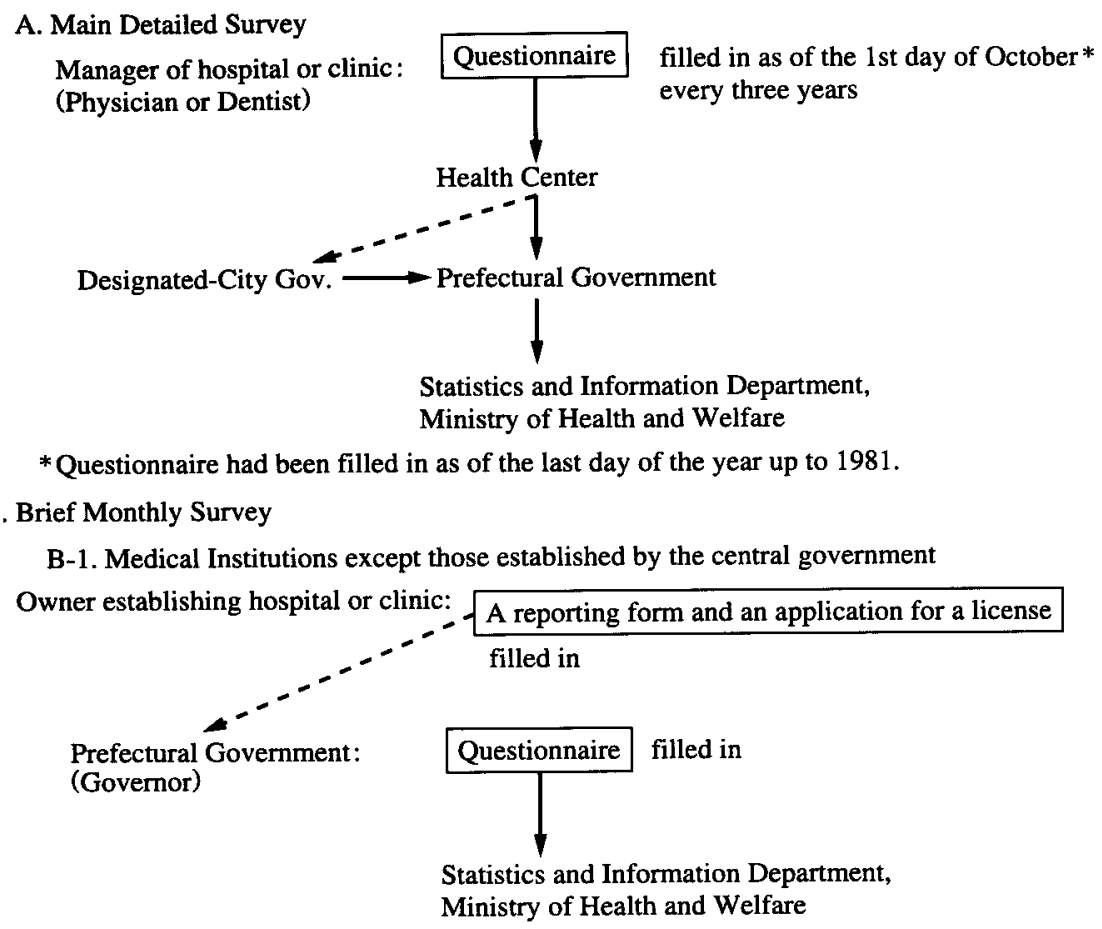

B-2. Medical Institutions established by the central government

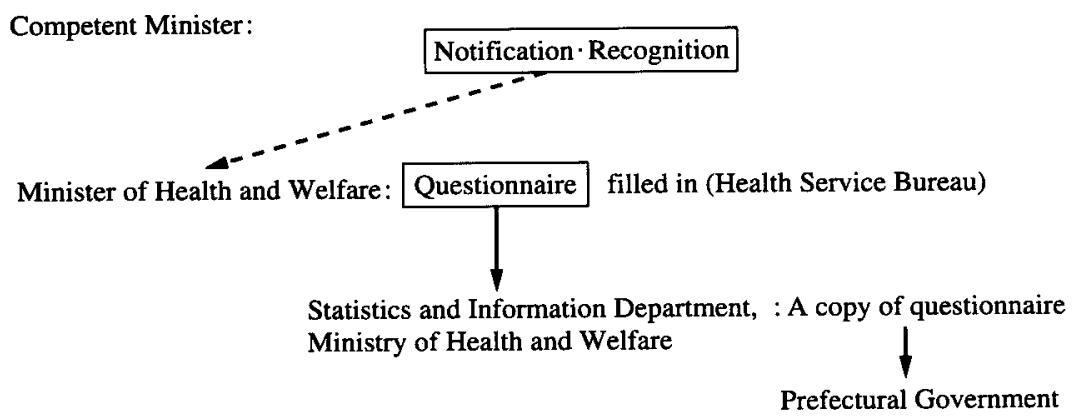

Figure 4. Census on Medical Care Institutions

Welfare Office. The collected questionnaires are sent to the Statistics and Information Department of the Ministry of Health and Welfare through the prefectural and, where applicable, the designated-city governments.

\section{Tabulation and Publication}

The Statistics and Information Department is responsible for the tabulation, and releases the results through publications and other media.

\section{Census on Medical Care Institutions (Figure 4)}

History

Before the formal establishment of the Survey on Medical Care Institutions, the reporting on the number of facilities, their geographical location and type of services provided had been included in the Statistical Report on Home Affairs.

After the first survey on medical care institutions was conducted in 1948, some improvements in the survey method and data collection procedure were made and they resulted in the establishment of the Survey on Medical Care Institutions, which has been conducted on a regular basis since 1953 .

In 1973, a major modification in the structural arrangement 
and procedure was made, dividing the survey into two portions, namely, the Main Detailed Survey and the Brief Monthly Survey.

\section{Purpose}

To provide data on the geographical distribution, characteristics, manpower and equipments of medical care institutions.

\section{Coverage}

All hospitals and clinics in Japan.

\section{Date}

The Main Detailed Survey is conducted as of 1 October every three years, and the Brief Monthly Survey is done as of the end of every month.

\section{Contents of Questionnaire}

(i) Main Detailed Survey

Name of medical care institution, address, type of ownership, number of beds, by diseases, equipments installed, specialty, and others.

(ii) Brief Monthly Survey (This survey is only for the institutions newly registered or those reporting changes).

Name of medical care institution, address, type of ownership, type of registration (establishment, abolition or suspension), number of beds by disease, specialty, and others.

\section{Data Collection Procedure}

The questionnaire filled in by a responsible person in each institution is submitted to the health center that administers the area where the medical care institution is located. Those collected questionnaires are sent to the Statistics and Information Department of the Ministry of Health and Welfare through prefectural and, where applicable, the designated-city governments.

\section{Tabulation and Publication}

The Statistics and Information Department is responsible for the tabulation and releases the results through publications and other media.

\section{Hospital Report (Figure 5)}

\section{History}

The Report was originated as the Weekly Hospital Report in 1945. In 1948 it was modified as a monthly report, together with the extension of the coverage of tuberculosis and leprosy hospitals, and renamed as the Hospital Report, with the enactment of the Medical Service Law.

The number of newborns and the number of employees have been added to the items of the report since 1968 and 1973 , respectively.

\section{Purpose}

The purpose of the Report is to provide data on the geographical distribution, present situation and utilization of hospitals.

\section{Coverage}

A 11 hospitals in Japan.

\section{Contents of Report Form}

a. Patient form (monthly)

Number of inpatients, outpatients, newborns, etc.

b. Employee form (annual)

Number of physicians, pharmacists, nurses, etc.

\section{Data Collection Procedure}

The report forms filled in by the responsible person of the hospitals are sent to the Ministry of Health and Welfare through the health centers and prefectural governments.

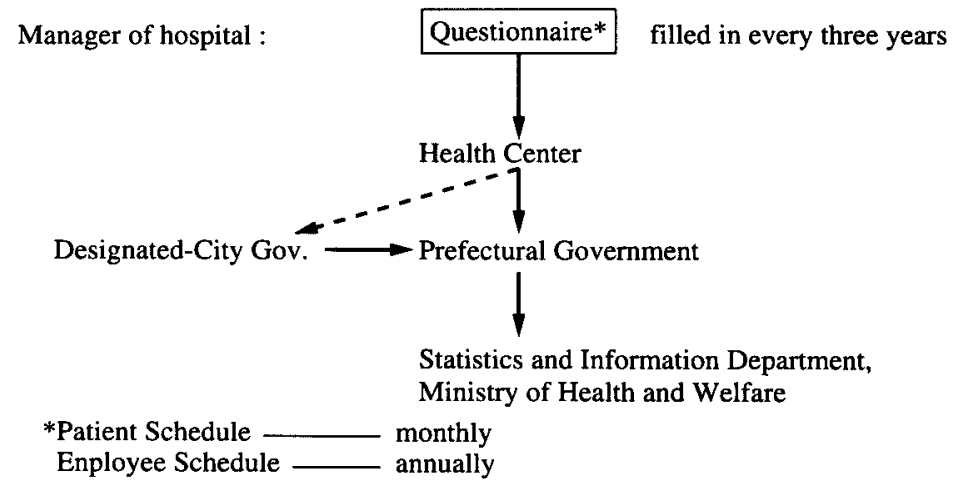

Figure 5. Hospital Report 


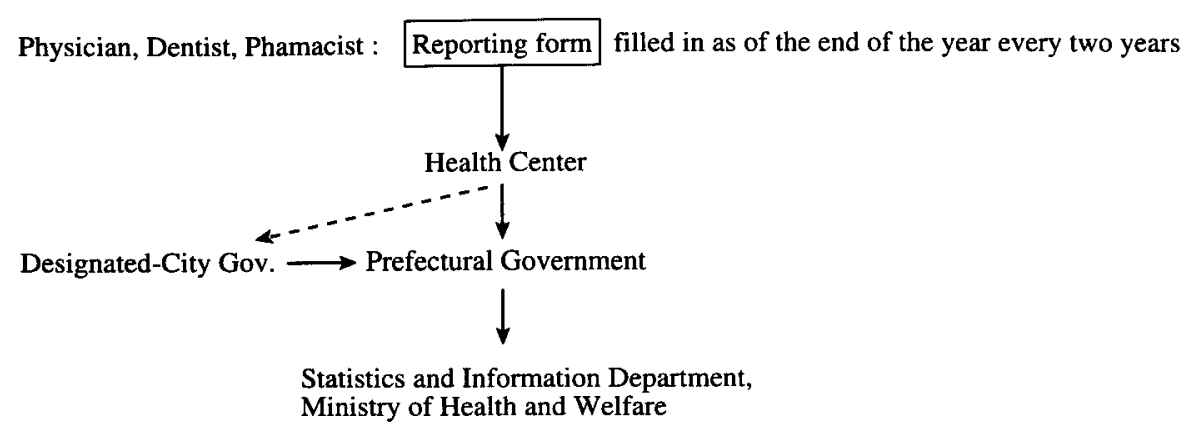

Figure 6. Survey of Physicians, Dentists, and Pharmacists

\section{Tabulation and Publication}

The Statistics and Information Department takes charge of the tabulation and releases the results through publications and other media.

\section{Survey on Physicians, Dentists and Pharmacists (Figure 6).}

\section{History}

Originally, the Survey on Physicians, Dentists and Pharmacists was included in the Statistical Report on Public Health Services started in 1874.

With the enactment of the Medical Practitioners Law and the Dentists Law in 1948 and with the amendment of the Pharmaceutical Affairs Law in 1954, the reporting forms on physicians, dentists and pharmacists were separated from the Statistical Report and constituted the forms for a new survey, the Survey on Physicians, Dentists and Pharmacists in 1954.

\section{Purpose}

To collect information on the number and geographical distribution of these health personnel.

\section{Coverage}

All physicians, dentists, and pharmacists registered in Japan.

Date

As of 31 December (since 1982 every two years).

\section{Contents of Reporting Forms}

Name, sex, date of birth, date of registration, registration number, main activity, and employment status.

\section{Data Collection Procedure}

The report form filled in by each professional is submitted to the health center. At the health center, editing work is done and the report is sent to the Statistics and Information Department via the prefectural government.

\section{Tabulation and Publication}

The Statistics and Information Department takes charge of the tabulation and releases the results through publications.

9. Statistical Report on Public Health Administration Services (Figure 7).

\section{History}

The Statistical Report on Home Affairs, the predecessor of the Statistical Report on Public Health Administration and Services, was initiated in 1886.

When the Ministry of Health and Welfare was established in 1938, it was newly enacted as the Statistical Report on Public Health Administration and Services.

The jurisdiction of the Report was transferred from the General Affairs Division of the Minister's Secretariat to the Statistics and Information Department in 1949 and thereafter there have been many changes in the reporting forms to meet

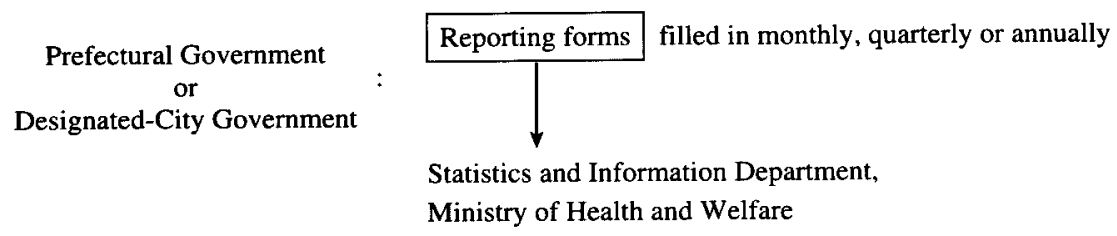

Figure 7. Statistical Report on Public Health Administration Services 
the administrative demands.

\section{Purpose}

To collect data on the present situation of the health administrative activities in the prefectural and designated-city governments.

\section{Coverage}

All prefectural and designated-city governments.

\section{Date}

As of 31 December, annually.

\section{Contents of Reporting Form}

All administrative activities about mental health, nutrition, leprosy, communicable diseases, venereal diseases, clinical examinations, environmental sanitation, food sanitation, veterinary sanitation, medical care inspections, dental technicians, public health nurses and pharmaceutical affairs in all the prefectural and designated-city govenments.

\section{Data Collection Procedure}

The reporting forms filled by the responsible persons in the prefectural and designated-city governments are sent to the Statistics and Information Department of the Ministry of Health and Welfare.

\section{Survey on Social Welfare Institutions}

\section{History}

The Statistical Report on Social Welfare Services, the origin of the Survey on Social Welfare Institutions, was made before 1956.

In 1956, the Survey on Social Welfare Institutions was initiated in order to collect data from each institution on the manpower and functions of the institution.

\section{Purpose}

To provide data on the geographical distribution and functions of the social welfare institutions.

\section{Coverage}

All social welfare institutions in Japan.

Date

As of 1 October, annually.

\section{Contents of Questionnaire}

Type of institution, name of institution, address, number of staff, capacity, and others.

\section{Data Collection Procedure}

The welfare offices deliver the questionnaires, which are filled in by the responsible person of the institution and sent to the welfare offices, and then to the Statistics and Information Department of the Ministry of Health and Welfare through the prefectural and designated-city governments.

\section{Tabulation and Publication}

The Statistics and Information Department takes charge of the tabulation and releases the results through publications and other media.

\section{National Nutrition Survey}

History

The First National Nutrition Survey was carried out in the Tokyo area in 1945 under the direction of the Commander of the Allied Forces. Since 1946, this survey has been executed on a nationwide scale each year.

\section{Purpose}

To provide data on nutrient intake and health status as the basis for implementing nutritional improvement.

\section{Coverage}

300 districts are randomly selected from a listing derived from the Comprehensive Survey of Living Conditions of People on Health and Welfare conducted in June or July each year, and all households and household members in those districts are surveyed. The sample comprises approximately 6,000 households and 20,000 members.

\section{Date}

In November, a dietary survey is conducted for three cosecuctive days excluding holidays, physical and biochemical examinations are conducted on a designated day.

\section{Contents of Survey}

(i) Dietary survey

a. sex, age and the level of physical activities of household members.

b. food intake by a weighing method in households.

(ii) Physical and biochemical examinations

Height and weight, blood pressure, and blood examination.

\section{Data Collection Procedure}

In the dietary survey, the trained dietitians in the health center interview subjects and collect questionnaires. Physical and biochemical examinations are conducted by doctors and public nurses at specified locations and collect questionnaires there. The collected questionnaires are sent to the Health Promotion and Nutrition Division of the Ministry of Health and Welfare through the prefectural and the designated-city governments. 
Tabulation and Publication

The Health Promotion and Nutrition Division is responsible for the tabulation, and releases the results through publications and other media.

\section{On-line data system of the Ministry of Health and Welfare (Figures 8 and 9)}

The Ministry of Health and Welfare organizes two common data systems on WISH (Wide-area Information-exchange
System for Health and Welfare administration), five systems for individual purposes on WISH and three independent systems. The common data systems have two functions ; (1) a bulletin board and electronic mail, (2) a reference of the common health statistics and the official documents of the Ministry of Health and Welfare. The WISH include also five individual systems ; (1) a supporting system for local health and medical care planning, (2) the administration system for national hospitals, (3) the information system for the results of medical examinations for infectious diseases, (4) the administration

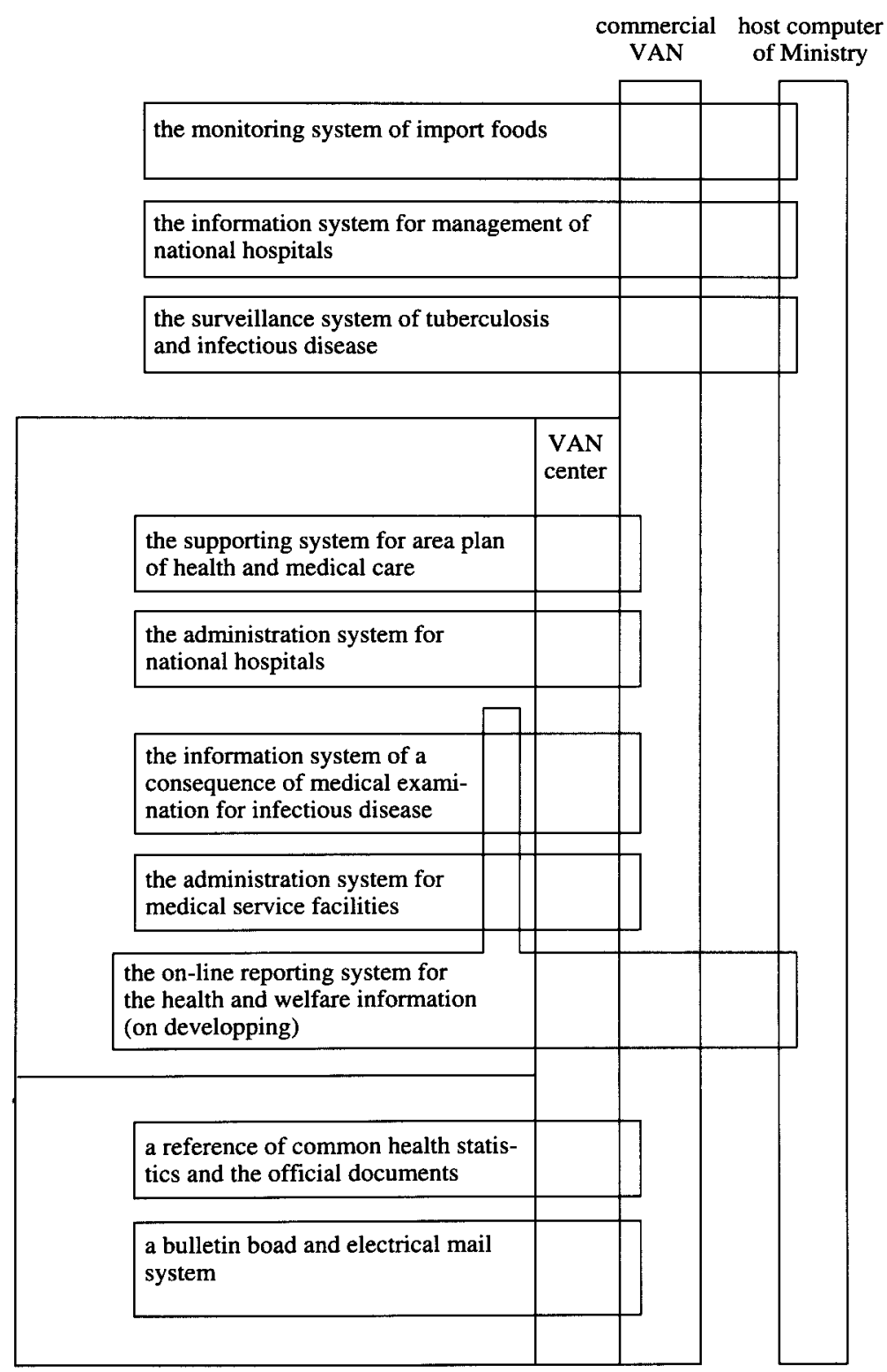

Figure 8. An outline of WISH (Wide-area Information-exchange System for Health and Welfare Administration) 


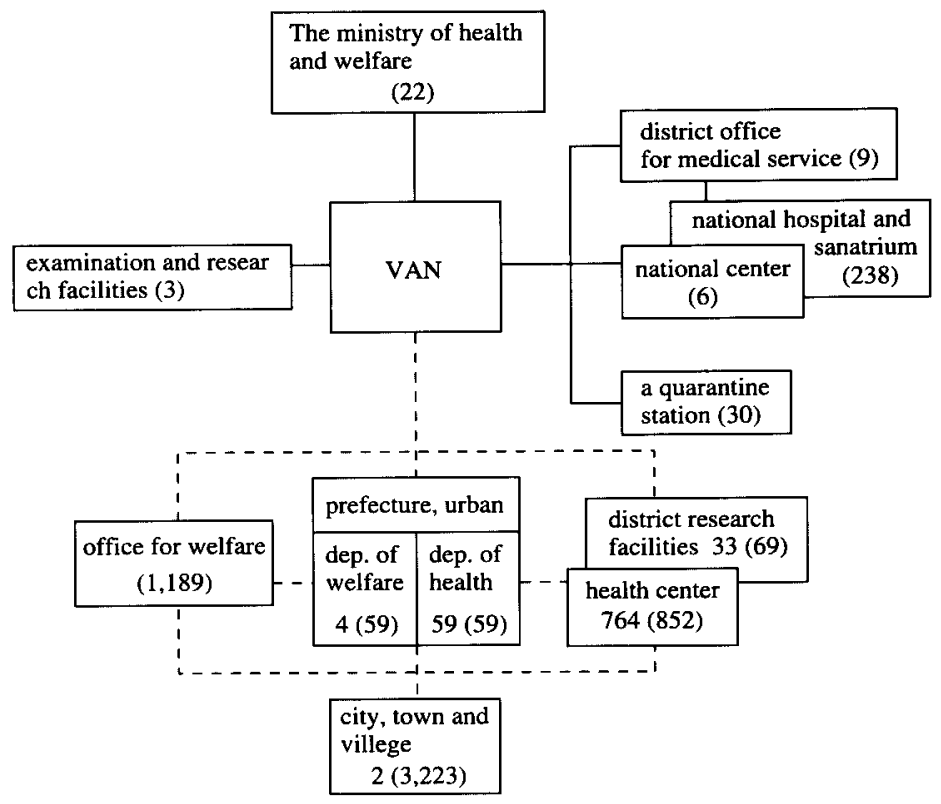

Figure 9. Network of WISH

system for medical service facilities and (5) the on-line system for reporting health and welfare information in obligation. However, the repo:ting system is still developing now. The monitoring system of imported foods, the on-line information system for management of national hospitals and the surveillance system of tuberculosis and infectious diseases are run directly by the Ministry of Health and Welfare. The WISH system is managed with commercial VAN. The supporting system for local health and medical care planning includes population size, vital statistics and various health and welfare data based on national surveillance and monitoring.

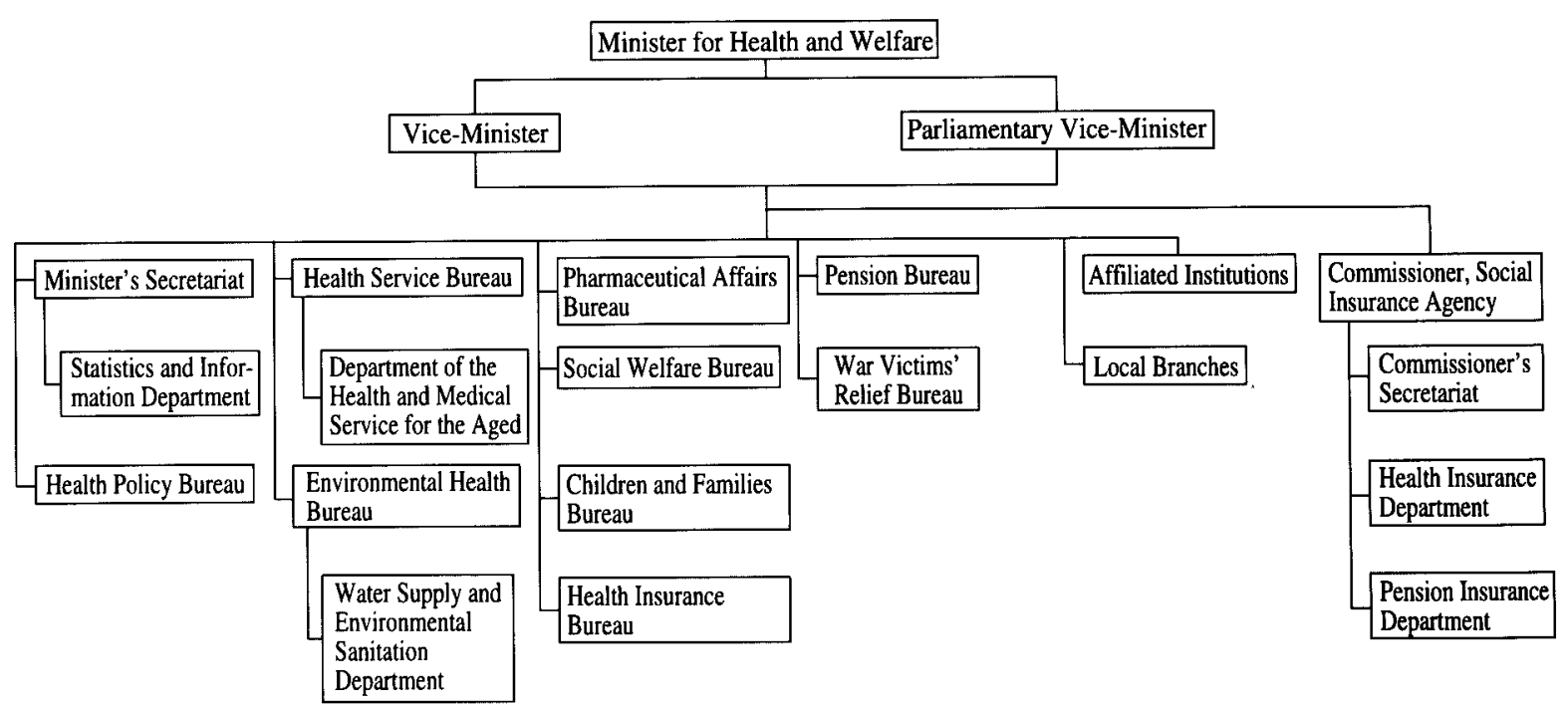

Annex 1. Organization chart of the Ministry of Health and Welfare 
1. Statistics on Artificial Abortion and Eugenic Operation

A. Artificial Abortion

Physician Designated by Japan Physicians' Association

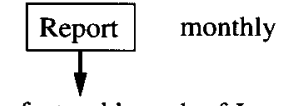

Prefectural branch of Japan

Association for Maternal Welfare

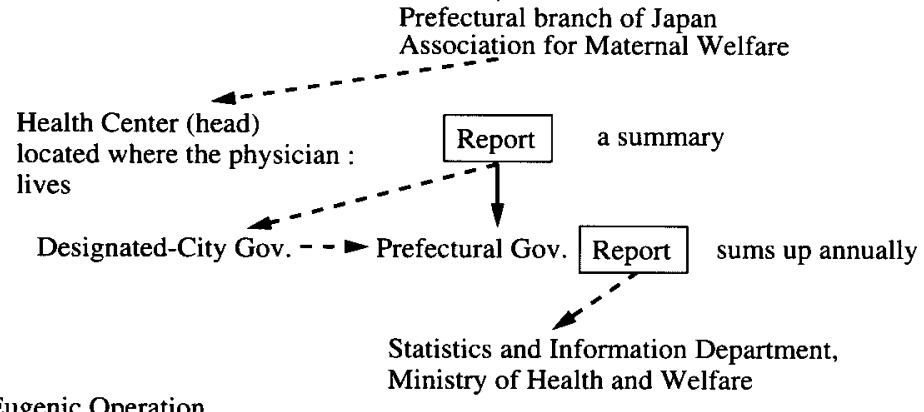

B. Eugenic Operation
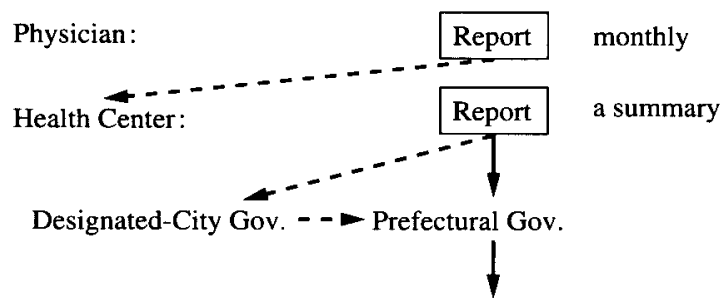

Statistics and Information Department, Ministry of Health and Welfare

2. Statistics on Activities for the Aged

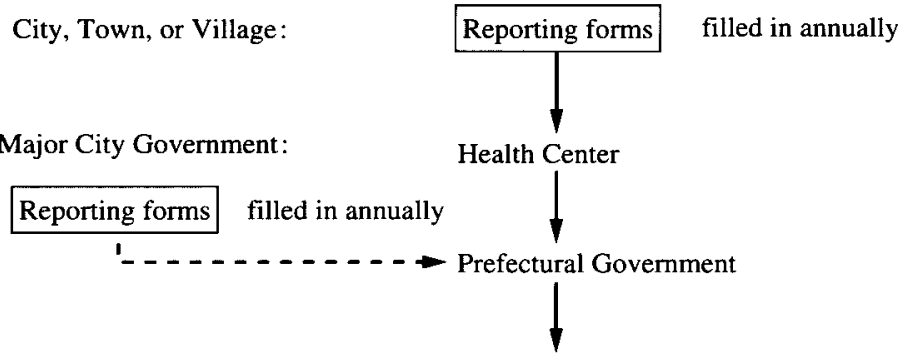

Statistics and Information Department Ministry of Health and Welfare

3. Statistics on Activities of Health Centers

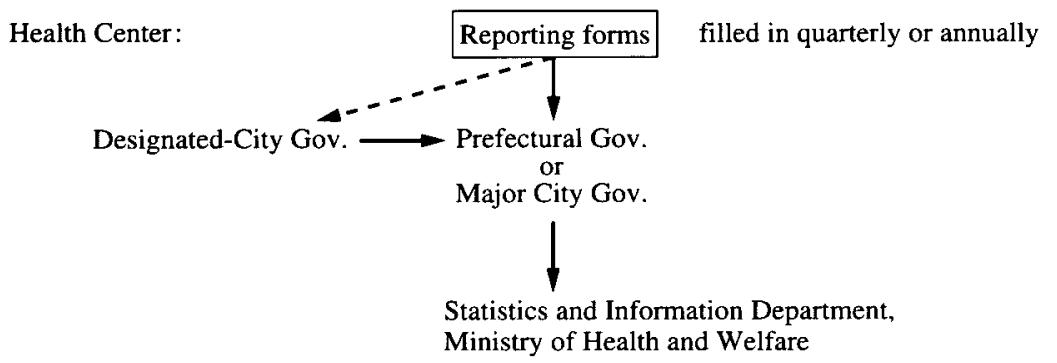

Annex II. Data flow charts of other health statistics 